\title{
Responsabilidade ambiental ou greenwash: uma análise da evidenciação ambiental das maiores empresas brasileiras
}

\section{Leandro Araújo Wickboldt ${ }^{1}$,*, Josicleide de Amorim Pereira Moreira $^{1}$, Maria do Rosário da Silva ${ }^{2}$, Jaelson dos Santos Araújo ${ }^{3}$, Jéssica Viana da Silva ${ }^{3}$, João Alves Pereira ${ }^{3}$}

${ }^{1}$ Universidade Federal de Alagoas. Campus Sertão. Unidade Santana do Ipanema. Rua Antonio Tavares, 197. Monumento. Santana do Ipanema-AL, Brasil. (CEP 57500-000). *E-mail: leandrowickboldt@hotmail.com.

${ }^{2}$ Programa de Pós-Graduação em Controladoria. Universidade Federal Rural de Pernambuco. Av. Santos Dumont, 420. Recife-PE, Brasil (CEP 52050-050).

${ }^{3}$ Curso de Graduação em Ciências Contábeis. Universidade Federal de Alagoas. Campus Sertão. Unidade Santana do Ipanema. Rua Antonio Tavares, 197. Monumento. Santana do Ipanema-AL, Brasil. (CEP 57500-000).

Resumo. As reivindicações sobre o desempenho ambiental corporativo aumentaram nos últimos anos como forma de exigir uma postura mais proativa das empresas quanto às questões de preservação do meio ambiente. Dessa forma, uma das maneiras de monitorar o desempenho ambiental corporativo é por meio da evidenciação (divulgação) com essa finalidade. Neste sentido, pesquisas científicas têm sido feitas para promover a avaliação da qualidade das informações ambientais, o denominado environmental disclosure. Contudo, cresceu também o greenwash, que é a comunicação que induz as pessoas a formarem crenças excessivamente positivas sobre práticas ambientais corporativas ou de produtos, que na realidade não são. Portanto, o estudo objetiva analisar o nível de evidenciação ambiental das dez maiores empresas, dentre as 1.000 , listadas no ranking da revista Valor Econômico, no ano de 2016, com ênfase na identificação da prática de greenwash nas empresas, no ano de 2015. Para tanto, foi adaptado um questionário para a análise do nível de evidenciação ambiental, empregando doze questões sobre práticas ambientais, atribuindo pontuação para cada empresa. Os resultados apontam que apesar de as empresas terem atingido, em média, 76\% do índice, quatro delas ficaram abaixo de 65\%, o que releva um fraco desempenho ambiental e indícios de greenwash. Além disso, a divulgação de planos e cumprimento de metas ambientais foi a questão menos atendida (30\% do total), revelando o baixo comprometimento com a viabilidade de longo prazo do negócio, que permeia à questão ambiental. Sustentabilidade; Comunicação corporativa; Evidenciação ambiental; Greenwash.
Recebido:

$13 / 06 / 2018$

Aceito:

$29 / 10 / 2018$

Publicado:

$31 / 12 / 2018$

Acesso aberto

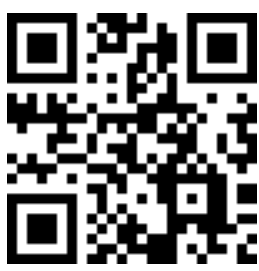

ORCID

다 0000-0002-9214-193X

Leandro Araújo

Wickboldt

D 0000-0002-4776-7255

Josicleide de Amorim

Pereira Moreira

(D) 0000-0003-0455-6535

Maria do Rosário da

Silva 
Abstract. Environmental responsibility or greenwash: An analysis of the environmental disclosure of the largest Brazilian companies. Claims about corporate environmental performance have increased in recent years as a way of requiring a more proactive position from companies as for environmental conservation issues. Thus, the corporate environmental performance may be monitored by the disclosure aimed at this purpose. In this sense, scientific research has been done to promote the evaluation of the environmental information quality, the so-called environmental disclosure. However, a bad practice named greenwash has also developed. Greenwash is a communication that induces people to form excessively positive beliefs about corporate environmental practices or about their products, which, in fact, are not positive. Therefore, this study aimed to analyze the level of environmental disclosure of the ten largest companies among those 1,000 ones listed in the ranking of the Valor Econômico magazine, in 2016, with emphasis on the identification of the greenwash practice in the companies, in 2015. For this purpose, a questionnaire was adapted to analyze the level of environmental disclosure, addressing twelve questions on environmental practices and assigning scores for each company. The results show that, although companies have reached, on average, $76 \%$ of the index, four of them were below $65 \%$, which indicates a weak environmental performance and signs of greenwash in this group. In addition, the disclosure of plans and compliance with environmental targets were the fewest met issues $(30 \%$ of the total), revealing the low commitment to the long-term viability of the business, which permeates the environmental issue.

Keywords: Corporate social responsibility; Sustainability; Corporate communication; Environmental disclosure;

\author{
D0000-0002-7647-5796 \\ Jaelson dos Santos \\ Araújo \\ 구 0000-0003-2965-7447 \\ Jéssica Viana da Silva \\ (1) 0000-0002-4579-3687 \\ João Alves Pereira
}

\section{Introdução}

0 termo desenvolvimento sustentável despontou na conferência da Organização das Nações Unidas (ONU) em 1972, sendo posteriormente definido pela Comissão Mundial sobre Meio Ambiente e Desenvolvimento (CMMAD), em 1987, e evidenciado no relatório Brundtland, como aquele capaz de atender "às necessidades do presente sem comprometer a capacidade das gerações futuras para atender às suas necessidades" (CMMAD, 1991, p. 46).

Neste contexto, compelidas pelas pressões externas, as empresas passaram a adotar ações mitigadoras de impactos ambientais ocasionados por suas atividades econômicas, vislumbrando, dessa forma, entre outros, a perenidade de seus negócios.

É sabido que a atividade empresarial influencia e é influenciada pela sociedade e pelo meio ambiente que a circunda. Assim, os impactos causados pelo uso dos recursos naturais são de interesse tanto da empresa quanto das comunidades local e global. Ensejando, portanto, que as entidades evidenciem por meio de relatórios de sustentabilidade os impactos de suas operações, bem como as ações minimizadoras da degradação ambiental. Assim, para realizar a divulgação de informações, vários são os padrões sugeridos para os relatórios que visam o 
diálogo com a sociedade no âmbito socioambiental, a exemplo do Global Reporting Initiative (GRI) o qual propõe um modelo de relatório de sustentabilidade empresarial envolvendo as dimensões econômica, social e ambiental (Castro et al., 2009). Em suma, tais relatórios defendem que deve haver um equilíbrio nos resultados alcançados pela empresa nos âmbito econômico, social e ambiental com o propósito de alcançar a sustentabilidade empresarial.

Contudo, tais relatórios devem ser analisados com olhar crítico a fim de verificar a coerência, consistência e proporcionalidade com relação aos benefícios alcançados pela empresa e o retorno que a mesma dá a sociedade. De modo a não incorrer no greenwash, expressão conhecida como "pincela verde", na qual algumas empresas adotam a fim de transparecer responsabilidade ambiental, mas que na verdade se constituem apenas como promoções de marketing.

Neste sentido, o presente artigo tem como objetivo geral analisar o nível de evidenciação ambiental das dez maiores, entre o ranking das 1000 empresas, listadas na revista Valor Econômico, com ênfase na identificação da prática de greenwash. Como objetivos específicos, descrever as características gerais das empresas pertencentes à amostra, mensurar em quais aspectos as empresas são melhores e piores no quesito desempenho ambiental, avaliar as melhores e piores empresas dentro da amostra em desempenho ambiental, verificando a existência de greenwash.

A temática em questão é a evidenciação empresarial (disclosure). Essa temática abrange uma série de relatórios periódicos elaborados e divulgados pelas companhias, de caráter obrigatório e voluntário, financeiros e não financeiros, com $o$ intuito de informar os stakeholders sobre suas atividades (Hendriksen e Van Breda, 1999). 0 reconhecimento da importância do equilíbrio de trocas com todas as partes relacionadas à entidade tais como, funcionários, clientes, fornecedores, governo e sociedade extrapola o reporte de informações financeiras, ampliando e moldando a linguagem dos negócios para atender um público maior (Ribeiro Filho et al., 2009). Sendo assim, a evidenciação não fica restrita aos informes obrigatórios (balanço patrimonial, demonstrações de resultado etc.), mas abrange também relatórios que visam a ampliar o nível de informação sobre a empresa (relatório de administração, relatórios de sustentabilidade etc.).

Evidências empíricas indicam que uma divulgação de qualidade pode melhorar a legitimidade das empresas (Wilmshurst e Frost, 2000), bem como reduzir a assimetria informacional, risco e custo de capital (Leland e Pyle, 1977). Assim, a evidenciação empresarial representa um esforço das organizações para manterem um canal permanente de comunicação não só com o mercado financeiro, importante fonte de financiamento de suas atividades, mas também com toda a sociedade.

Um dos aspectos da evidenciação empresarial mais valorizado pelo mercado atualmente é a evidenciação socioambiental. Apesar de voluntária, a evidenciação socioambiental é considerada pela B3 (2005) um aspecto fundamental a ser destacado nas empresas de capital aberto, pois representam um esforço adicional e dispendioso que transmitirá ao mercado o compromisso da empresa com a viabilidade futura do negócio.

A B3 estimula a responsabilidade socioambiental corporativa (RSC) por meio do Índice de Sustentabilidade Empresarial (ISE), que divulga o desempenho no mercado de capitais das empresas ambientalmente eficientes. Tal índice é inspirado no primeiro índice que incorporou a sustentabilidade, o Dow Jones Sustainability Index (DJSI), da New York Exchange (NYSE). Por sua vez a Comissão de Valores Mobiliários (CVM, 2002) também estimula a RSC por meio do Parecer $n^{0}$ 15/1997, que sugere que as empresas apresentem, no relatório de 
administração, as informações relativas aos investimentos socioambientais e sua conduta em relação às questões ecológicas.

Já o Conselho Federal de Contabilidade (CFC) aprovou a NBC-T no 15/2004 (CFC, 2004), com o objetivo de estabelecer as orientações para divulgação das informações de natureza social e ambiental. Segundo o regulamento, as informações devem ser configuradas na forma de relatórios com finalidade específica. Além disso, fica claro que as informações devem ser apresentadas na forma comparativa, ou seja, sempre precedidas das informações do ano anterior e ser objeto de auditoria.

Isto posto, percebe-se a valorização das informações sociais e ambientais pelo mercado e pelas autoridades. Degenhart et al. (2016) constataram que a maioria das companhias brasileiras de capital aberto divulgou, entre 2010 e 2013, informações dessa natureza, sendo que $25 \%$ em relatório de sustentabilidade.

Todavia, o aumento do volume de evidenciação socioambiental não significa, necessariamente, melhoria do engajamento das empresas a estas causas. A iniciativa privada vem se apropriando do discurso "sustentável" como uma grife, uma marca a ser utilizada, em troca de valorização de sua imagem e legitimidade social. Ocasionalmente esses agentes, utilizam a "linguagem verde" como discurso infundado, transmitindo uma imagem de responsabilidade socioambiental que nem sempre condiz com a realidade. Para denotar essa prática de marketing verde sem fundamento em políticas, programas e ações concretas e consistentes que resultem em investimentos que possam ser percebidos pela sociedade.

0 termo greenwash foi utilizado pela primeira vez na pesquisa de Greer e Bruno (1998) para designar ações de "responsabilidade ambiental" empreendidas por algumas empresas que não passam de autopromoção, ou seja, meras ações de marketing. Em sua pesquisa os autores analisaram 20 corporações globais das áreas de química, energética, madeireira e pesqueira, constatando o greenwash corporativo com os efeitos prejudiciais do comportamento real das companhias.

No Brasil foram encontrados poucos estudos que procuram investigar se os programas e ações no âmbito socioambiental das empresas podem ser considerados RSC ou greenwash (Lins e Silva, 2009; Silva e Oliveira, 2013; Turano et al., 2014).

Com o intuito de identificar se a prática condiz com o discurso, Turano et al. (2014) compararam os documentos divulgados por uma multinacional, presente em 35 países, com notícias veiculadas na imprensa e entrevistas com funcionários. Os autores constataram que há falhas na política de sustentabilidade da empresa. Em outra pesquisa Silva e Oliveira (2013) analisaram as peças publicitárias (sites, folders, catálogos e outdoors) de empreendimentos imobiliários no Município de Caruaru, Pernambuco, identificando que houve certo nível de propaganda enganosa, a luz do art. 36, do Código Brasileiro de Autorregulamentação Publicitária, do Conselho Nacional de Autorregulamentação Publicitária (CONAR, 1977), referente à autenticidade publicitária e a realidade do produto/serviço no que tange às características sustentáveis.

Lins e Silva (2009) estudaram os relatórios (2005-2006) das companhias brasileiras de papel e celulose, listadas no ISE da B3, com o propósito de avaliar a transparência e adequação das informações ambientais. Para tanto elaboraram um instrumento pontuando: (1) valor dos investimentos em meio ambiente; (2) multas e processos judiciais ambientais em curso; (3) eventos patrocinados; (4) prêmios e certificações; (5) metas e prestação de contas; (6) emissões, efluentes e resíduos; (7) integrante do Dow Jones Sustainability Index (DJSI); (8) consumo de água; (9) consumo de energia; (10) 
governança corporativa. Os autores atribuíram pontuação maior aos quesitos de maior complexidade de cumprimento e menor pontuação para àqueles quesitos mais fáceis.

Em seus resultados, Lins e Silva (2009) constataram que duas das três empresas analisadas alcançaram pontuação próxima à máxima, no entanto uma delas atingiu pouco mais que $50 \%$. 0 que pode ser considerado temerário em se tratando de uma das maiores empresas de papel e celulose do Brasil.

Internacionalmente, foram encontrados alguns estudos que discutem mais profundamente o conceito de greenwash, à luz de sua multidisciplinaridade, e avaliam os efeitos maléficos desta prática por parte das empresas (Chen e Chang, 2013; Lyon e Montgomery, 2013, 2015; Cooper, 2015).

Chen e Chang (2013) definem greenwash como sendo o ato de enganar os consumidores em relação às práticas ambientais de uma empresa ou aos benefícios ambientais de um produto ou serviço. Os autores desenvolveram um estudo junto a consumidores taiwaneses de produtos eletrônicos e constataram que o greenwash está prejudicando a confiança do consumidor com a publicidade. Por sua vez, Lyon e Montgomery (2013) levantaram que a propaganda verde aumentou 300\%, entre 2006 e 2009 , e que $75 \%$ das empresas listadas na bolsa de valores dos Estados Unidos possuem seções em seus websites dedicadas as suas políticas e desempenho social e ambiental. Os autores examinaram múltiplos casos, incluindo um "desastre" em redes sociais do McDonalds ao lançar uma campanha que foi abominada por seus stakeholders.

Mais tarde, Lyon e Montgomery (2015) realizaram uma síntese das pesquisas sobre greenwash, buscando catalogar as variedades e os impactos, que ocorre tanto em nível de produto quanto corporativo, defendendo que uma noção ampla consistente para o termo deve englobar toda e qualquer comunicação que induz os receptores a adotar crenças excessivamente positivas sobre o desempenho ambiental de uma organização.

Assim, as formas de greenwash encontradas na literatura por Lyon e Montgomery (2015) foram:

- Evidenciação seletiva: A evidenciação seletiva apresenta resultados conflitantes. Alguns estudos constatam que empresas com piores resultados ambientais têm maiores níveis de evidenciação ambiental, outros constatam ao contrário;

- Declarações e políticas vazias: Tratam-se de promessas e políticas que as empresas realmente não conseguem praticar. Estudos retratam que tal prática em empresas com fraca reputação ambiental pode reduzir seu risco intrínseco, sugerindo que os investidores são influenciados por "conversa barata";

- Certificações e rótulos duvidosos: São os certificados, como ISO 14001 e etiquetas verdes em produtos, que podem não representar real desempenho ambiental superior. Os achados são diversos, pois nos Estados Unidos a certificação ISO 14001 impactou positivamente na conformidade regulamentar, mas no México e no Canadá não passou de um ritual para impressionar o público externo;

- Programas voluntários públicos ineficazes: A participação de empresas em programas lançados pelo governo podem não levar a melhorias ambientais. Estudos reportam que as primeiras empresas a aderir reduzem a poluição, mas as que entram posteriormente não.

- Narrativa e discursos enganosos: Estudos por meio de análise de conteúdo em relatórios procuram identificar estratégias retóricas aplicadas em níveis micro e macro-discursos para moldar opiniões avaliativas sobre o desempenho ambiental das 
empresas e evitar acusações de greenwash;

\section{- Imagens imaginativas} enganosas: Inúmeras marcas de luxo utilizam símbolos de biodiversidade (crocodilos, cavalos, jaguares, etc.) em seus logotipos, utilizando a semiótica para modelar o processo pelo qual seus consumidores decodificam a relação das marcas de alto padrão com a sustentabilidade.

Os impactos danosos do greenwash, documentados por Lyon e Montgomery (2015), encontram-se a nível das empresas e da sociedade. Sendo que as empresas têm sido punidas pela prática de greenwash tanto com a perda de consumidores quanto por piores resultados financeiros. Em termos de sociedade o greenwash está provocando uma descrença geral quanto à sustentabilidade, dificultando a identificação de práticas consistentes de responsabilidade socioambiental corporativa.

Assim, ratifica-se à importância do tema em criar meios para que os stakeholders possam melhor identificar e se proteger de práticas de greenwash, bem como devido à escassez de estudos no mercado brasileiro.

\section{Materiais e métodos}

\section{Natureza da pesquisa}

A pesquisa teve por objetivo analisar o nível de evidenciação ambiental das dez maiores, entre 0 ranking das 1000 empresas, listadas na revista Valor Econômico ${ }^{\circledR}$, com ênfase na identificação da prática de greenwash. Diante disto, foi classificada como analítica, já que pretendeu analisar os fatos relacionados com as particularidades da investigação. Quanto aos meios foi classificada como qualitativa, a qual Richardson (2007) afirma ser esta uma tentativa de entender as características situacionais e particulares de um determinado fenômeno de estudo. No que tange a tipologia, adotou-se um estudo de caso múltiplo, uma vez que foi feito um comparativo entre as dez maiores empresas (Roesch, 2005). A coleta de dados se deu de fontes secundárias, por se tratar de material pronto e produzido pela empresa, sendo os relatórios anuais de sustentabilidade ou similares.

\section{Critérios de seleção da amostra e coleta de dados \\ Foram selecionadas as dez} maiores empresas brasileiras pelo critério da receita líquida, no ranking das 1000 maiores da revista Valor Econômico, no ano de 2016, salientando ser com base em dados de 2015. Essas dez empresas representam $31,5 \%$ da receita total das mil maiores, revelandose bastante representativa a amostra (Tabela 1).

A coleta de dados foi realizada nos sites das empresas, buscando por relatórios de sustentabilidade de 2016, pelo fato de conter informações mais detalhadas sobre a relação da empresa com o meio ambiente.

\section{Instrumento de análise do nível de evidenciação ambiental \\ Visando à padronização da} análise de cada empresa, foi elaborado um instrumento que contenha um conjunto de índices que possibilite, de forma comparativa, verificar o nível de evidenciação e se existe acoplamento das informações prestadas com a prática danosa de greenwash. A escolha dos quesitos que compuseram o instrumento tomou como base o estudo de Lins e Silva (2009), o qual inseriu dez questões, adaptadas do formulário enviado pela B3 às empresas para composição do ISE (Tabela 2). 
Tabela 1. Dez maiores empresas por maior receita líquida.

\begin{tabular}{l|c|c|c|c}
\hline Empresa & Sede & Setor de Atividade & $\begin{array}{c}\text { Receita Líquida (R\$ } \\
\text { milhões) }\end{array}$ & $\begin{array}{c}\text { Lucro Líquido (R\$ } \\
\text { milhões) }\end{array}$ \\
\hline Petrobras & RJ & Petróleo e Gás & $321.638,00$ & $-35.171,00$ \\
\hline JBS & SP & Alimentos e Bebidas & $162.914,00$ & $5.128,60$ \\
\hline Vale & RJ & $\begin{array}{c}\text { Metalurgia e } \\
\text { Mineração }\end{array}$ & $85.499,20$ & $-45.996,60$ \\
\hline Ultrapar & SP & Petróleo e Gás & $75.655,30$ & $1.513,00$ \\
\hline Raizen & SP & Petróleo e Gás & $74.109,20$ & $2.378,00$ \\
\hline GPA & SP & Comércio Varejista & $69.115,00$ & -314 \\
\hline Odebrecht & SP & $\begin{array}{c}\text { Construção e } \\
\text { Engenharia }\end{array}$ & $57.463,10$ & 890,00 \\
\hline Braskem & BA & $\begin{array}{c}\text { Química e } \\
\text { Petroquímica }\end{array}$ & $47.283,00$ & $2.898,80$ \\
\hline Ambev & SP & Alimentos e Bebidas & $46.720,10$ & $12.879,10$ \\
\hline Cosan & SP & Petróleo e Gás & $43.666,50$ & 666,60 \\
\hline
\end{tabular}

Fonte: Valor Econômico (2016).

Tabela 2. Questões abordadas para análise da qualidade da evidenciação ambiental.

\begin{tabular}{c|l|c}
\hline Item & \multicolumn{1}{|c|}{ Informação Evidenciada } & Pontuação \\
\hline $\mathbf{1}$ & $\begin{array}{l}\text { Multas recebidas e processos judiciais em curso relativos a aspectos } \\
\text { ambientais }\end{array}$ & $\mathbf{2 , 0 0}$ \\
\hline $\mathbf{2}$ & Prestação de contas das metas ambientais previstas no ano anterior & $\mathbf{2 , 0 0}$ \\
\hline $\mathbf{3}$ & Emissões, efluentes e resíduos comparativos com os anos anteriores & $\mathbf{2 , 0 0}$ \\
\hline $\mathbf{4}$ & Consumo de água em comparação com o ano anterior & $\mathbf{2 , 0 0}$ \\
\hline $\mathbf{5}$ & Consumo de energia comparativo com o ano anterior & $\mathbf{2 , 0 0}$ \\
\hline $\mathbf{6}$ & Integrante do índice Dow Jones de Sustentabilidade (DJSI) & $\mathbf{1 , 0 0}$ \\
\hline $\mathbf{7}$ & $\begin{array}{l}\text { Integrante do índice de sustentabilidade (ISE) da BM\&F Bovespa (B3 novo } \\
\text { nome) }\end{array}$ & $\mathbf{1 , 0 0}$ \\
\hline $\mathbf{8}$ & $\begin{array}{l}\text { Continuidade de apresentação de relatório com finalidade específica } \\
\text { (relatório de sustentabilidade ou afins) }\end{array}$ & $\mathbf{1 , 0 0}$ \\
\hline $\mathbf{9}$ & Valor dos investimentos ambientais & $\mathbf{0 , 5 0}$ \\
\hline $\mathbf{1 0}$ & Prêmios e certificados relativos ao meio ambiente & $\mathbf{0 , 5 0}$ \\
\hline $\mathbf{1 1}$ & Eventos ambientais patrocinados pela empresa & $\mathbf{0 , 2 5}$ \\
\hline $\mathbf{1 2}$ & $\begin{array}{l}\text { Listagem em algum dos segmentos diferenciados de Governança Corporativa } \\
\text { (N1, N2 ou Novo Mercado) }\end{array}$ & $\mathbf{0 , 2 5}$ \\
\hline & Pontuação máxima & $\mathbf{1 4 , 5}$ \\
\hline
\end{tabular}

Fonte: Adaptado de Lins e Silva (2009).

0 instrumento inovou ao inserir duas questões, a listagem da empresa no ISE da B3 (Q. 7) e a continuidade de apresentação de relatório de sustentabilidade (Q. 8).

Considera-se que a pontuação completa deva ser conferida a empresa que atende plenamente o quesito.
Havendo a possibilidade de ser atribuída pontuação parcial (metade ou menos). Por exemplo, caso seja divulgado o consumo de água ou energia (questões 4 e 5) do ano do relatório sem comparar com anos anteriores, recebia o valor de 1 ponto de 2 da questão. 
Quanto maior a pontuação alcançada, maior a propensão de a empresa ter responsabilidade ambiental, enquanto menores pontuações aumentam as chances de a empresa ser praticante de greenwash.

\section{análise \\ Aplicação do instrumento de \\ Para localização do conteúdo de} interesse e responder as questões do instrumento de pesquisa, foram empregadas palavras-chave em busca dos relatórios de sustentabilidade (Tabela 3 ).

Tabela 3. Palavras-chave por questão de pesquisa.

\begin{tabular}{|c|c|c|}
\hline Item & Informação evidenciada & Palavras-chave \\
\hline 1 & $\begin{array}{l}\text { Multas recebidas e processos judiciais } \\
\text { em curso relativos a aspectos } \\
\text { ambientais }\end{array}$ & $\begin{array}{l}\text { Multa(s); } \quad \text { autuação(ões); } \\
\text { penalidade(s); judicial(ais). }\end{array}$ \\
\hline 2 & $\begin{array}{l}\text { Prestação de contas das metas } \\
\text { ambientais previstas no ano anterior }\end{array}$ & Meta(s) ambiental(ais); prestação(ões) de contas. \\
\hline 3 & $\begin{array}{l}\text { Emissões, efluentes e resíduos } \\
\text { comparativos com os anos anteriores }\end{array}$ & Emissão(ões); efluente(s); resíduo(s). \\
\hline 4 & $\begin{array}{l}\text { Consumo de água em comparação com } \\
\text { o ano anterior }\end{array}$ & Água; recurso(s) hídrico(s). \\
\hline 5 & $\begin{array}{l}\text { Consumo de energia comparativo com } \\
\text { o ano anterior }\end{array}$ & Energia; elétrica; combustível(eis). \\
\hline 6 & $\begin{array}{l}\text { Integrante do índice Dow Jones de } \\
\text { Sustentabilidade (DJSI) }\end{array}$ & $\begin{array}{l}\text { Pesquisa na área de relação com investidores da } \\
\text { cia. }\end{array}$ \\
\hline 7 & 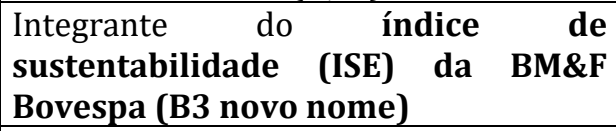 & $\begin{array}{l}\text { Pesquisa na área de relação com investidores da } \\
\text { cia. }\end{array}$ \\
\hline 8 & $\begin{array}{l}\text { Continuidade de apresentação de } \\
\text { relatório com finalidade específica } \\
\text { (relatório de sustentabilidade ou afins) }\end{array}$ & $\begin{array}{l}\text { Pesquisa na área de relação com investidores da } \\
\text { cia. }\end{array}$ \\
\hline 9 & Valor dos investimentos ambientais & Investimento(s) ambiental(ais). \\
\hline 10 & $\begin{array}{l}\text { Prêmios e certificados relativos ao } \\
\text { meio ambiente }\end{array}$ & Prêmio(s); certificado(s). \\
\hline 11 & $\begin{array}{l}\text { Eventos ambientais patrocinados pela } \\
\text { empresa }\end{array}$ & $\begin{array}{l}\text { Evento(s); patrocínio(s); } \\
\text { patrocinado(s). }\end{array}$ \\
\hline 12 & $\begin{array}{l}\text { Listagem em algum dos segmentos } \\
\text { diferenciados } \\
\text { Corporativa (N1, N2 ou Novo Mercado) }\end{array}$ & Site da B3 \\
\hline
\end{tabular}

\section{Resultados e discussão}

\section{Descrição do perfil das empresas da amostra}

Inicialmente, buscou-se conhecer a origem do capital das empresas participantes da pesquisa. Foi constatado que a maioria das empresas $(80 \%)$ tem a origem do capital genuinamente brasileiro, a exceção da Raízen e da Ambev, as quais contam com recursos estrangeiros (20\%).

Em sequência, foi examinado o desempenho econômico-financeiro das empresas (Tabela 4). 
Tabela 4. Earnings before interest, taxes, depreciation and amortization (Ebtida). Margem líquida (ML), Margem operacional (MO).

\begin{tabular}{l|c|c|c|c|c}
\hline Empresa & $\begin{array}{c}\text { Receita } \\
\text { líquida } \\
\text { (R\$ milhões) }\end{array}$ & $\begin{array}{c}\text { Lucro líquido } \\
\text { (R\$ milhões) }\end{array}$ & $\begin{array}{c}\text { Ebitda (R\$ } \\
\text { milhões) }\end{array}$ & ML & Mo \\
\hline Petrobras & $321.638,00$ & $-35.171,00$ & $73.860,10$ & $-10,93 \%$ & $22,96 \%$ \\
\hline JBS & $162.914,00$ & $5.128,60$ & $12.829,90$ & $3,15 \%$ & $7.88 \%$ \\
\hline Vale & $85.499,20$ & $-45.996,60$ & $-14.348,70$ & $-53,80 \%$ & $-16,78 \%$ \\
\hline Ultrapar & $75.655,30$ & $1.513,00$ & $3.964,20$ & $2,00 \%$ & $5,24 \%$ \\
\hline Raizen & $74.109,20$ & $2.378,00$ & $6.363,50$ & $3,21 \%$ & $8,59 \%$ \\
\hline GPA & $69.115,00$ & -314 & $2.568,00$ & $-0,45 \%$ & $3,72 \%$ \\
\hline Odebrecht & $57.463,10$ & 890,00 & $5.809,30$ & $1,55 \%$ & $10,11 \%$ \\
\hline Braskem & $47.283,00$ & $2.898,80$ & $9.164,90$ & $6,13 \%$ & $19,38 \%$ \\
\hline Ambev & $46.720,10$ & $12.879,10$ & $21.853,10$ & $27,57 \%$ & $46,77 \%$ \\
\hline Cosan & $43.666,50$ & 666,60 & $4.609,90$ & $1,53 \%$ & $10,56 \%$ \\
\hline
\end{tabular}

Em relação à margem líquida (ML) aponta-se a Ambev com o maior desempenho de 27,57\%, significando dizer que seu grau de rentabilidade é considerado elevado para seus acionistas. Seguida desta, tem-se a Braskem com 6,13\%. Já indo ao contraponto, ou seja, as duas menores ML são da Vale, com $-53,80 \%$, e da Petrobras com $-10,93 \%$.

Já em relação à margem operacional (MO), que tem como propósito revelar o lucro para a empresa, as companhias Ambev, Petrobras e Braskem apresentaram resultados superiores às demais. Neste quesito, a Vale apresentou um resultado negativo de $-16,78 \%$, destacando-se como o pior desempenho econômico-financeiro, dentre as dez.

A análise conjunta desses indicadores se faz relevante, pois empresas que possuem margens maiores, são mais lucrativas, porém seus resultados devem ser analisados em contexto maior, levando-se em consideração seus concorrentes e outros fatores externos, pois há situações que as empresas sacrificam suas margens liquidas para obter benefícios futuros.

A frequência de divulgação de relatórios com finalidade específica de comunicar aos stakeholders os programas, estratégias e ações de sustentabilidade da empresa é um fator de grande importância. Assim, examinouse a existência de constância entre o primeiro e o último ano de publicação desse tipo de relatório, disponíveis nos sites das empresas, sem ter havido "quebra" de sequência. Esta frequência pode revelar uma consistência nos propósitos da empresa, pesando positivamente para a imagem da mesma.

As empresas começaram a publicar, em média, a partir de 2006, tendo a Ambev iniciado em 2000, portanto já com 16 anos de constância.

Das empresas pesquisadas apenas a Cosan não manteve frequência de divulgação dos relatórios (Tabela 5).

\section{Análise do nível de evidenciação ambiental}

A seguir será analisado o nível de evidenciação ambiental das empresas da amostra, propósito principal deste estudo. Para tanto, a Tabela 6 expõe a pontuação por empresa e por questão. Para fins de análise será considerada empresa com indícios de greenwash aquelas com escore inferior à média, assim como procedido em estudos anteriores (Rosa et al., 2009). 
Tabela 5. Frequência de divulgação dos relatórios.

\begin{tabular}{l|c}
\hline Empresas & Frequência \\
\hline Petrobras & Sim \\
\hline JBS & Sim \\
\hline Vale & Sim \\
\hline Ultrapar & Sim \\
\hline Raizen & Sim \\
\hline GPA & Sim \\
\hline Odebrecht & Sim \\
\hline Braskem & Sim \\
\hline Ambev & Sim \\
\hline Cosan & Não \\
\hline
\end{tabular}

$\mathrm{Na}$ dimensão por questão, com base na Tabela 6, ficou evidenciado que em relação às multas recebidas e processos judiciais (Q.1) em curso relativos aos aspectos ambientais, as empresas que obtiveram maior performance foram a Petrobrás, Vale,
Odebrecht, Braskem, Ambev e Cosan. Enquanto que as empresas JBS, Ultrapar, Raízen e GPA, obtiveram baixa performance, visto que não evidenciaram durante o período multas ou processos judiciais em curso relacionadas ao aspecto ambiental.

Tabela 6. Análise das variáveis da pesquisa.

\begin{tabular}{|c|c|c|c|c|c|c|c|c|c|c|c|c|c|}
\hline Item & Informação Evidenciada & Pontuaçâo & Petrobras & JBS & Vale & Ultrapar & Raizen & GPA & Odebrecht & Braskem & Ambev & Cosan & Questão \\
\hline 1 & $\begin{array}{l}\text { Multas recebidas e processos } \\
\text { judiciais em curso relativos a } \\
\text { aspectos ambientais }\end{array}$ & 2,00 & 2,00 & 0,00 & 2,00 & 0,00 & 2,00 & 0,00 & 2,00 & 2,00 & 2,00 & 2,00 & 14,00 \\
\hline 2 & $\begin{array}{l}\text { Prestaçăo de contas das metas } \\
\text { ambientais previstas no ano } \\
\text { anterior }\end{array}$ & 2,00 & 0,00 & 0,00 & 2,00 & 0,00 & 0,00 & 2,00 & 0,00 & 0,00 & 2,00 & 0,00 & 6,00 \\
\hline 3 & $\begin{array}{l}\text { Emissões, efluentes e resíduos } \\
\text { comparativos com os anos } \\
\text { anteriores }\end{array}$ & 2,00 & 2,00 & 2,00 & 2,00 & 2,00 & 1,00 & 1,33 & 2,00 & 2,00 & 1,33 & 2,00 & 17,66 \\
\hline 4 & $\begin{array}{l}\text { Consumo de água em comparaçăo } \\
\text { com o ano anterior }\end{array}$ & 2,00 & 2,00 & 2,00 & 2,00 & 2,00 & 2,00 & 2,00 & 2,00 & 2,00 & 2,00 & 0,00 & 18,00 \\
\hline 5 & $\begin{array}{l}\text { Consumo de energia comparativo } \\
\text { com o ano anterior }\end{array}$ & 2,00 & 2,00 & 2,00 & 2,00 & 2,00 & 2,00 & 2,00 & 2,00 & 2,00 & 2,00 & 2,00 & 20,00 \\
\hline 6 & $\begin{array}{l}\text { Integrante do indice Dow Jones de } \\
\text { Sustentabilidade (DJSI) }\end{array}$ & 1,00 & 1,00 & 1,00 & 1,00 & 1,00 & 1,00 & 1,00 & 0,00 & 1,00 & 1,00 & 1,00 & 9,00 \\
\hline 7 & $\begin{array}{l}\text { Integrante do índice de } \\
\text { sustentabilidade (ISE) da BM\&F } \\
\text { Bovespa (B3 novo nome) }\end{array}$ & 1,00 & 0,00 & 0,00 & 1,00 & 0,00 & 0,00 & 1,00 & 0,00 & 1,00 & 1,00 & 0,00 & 4,00 \\
\hline 8 & $\begin{array}{l}\text { Continuidade de apresentação de } \\
\text { relatório com finalidade especifica } \\
\text { (relatório de sustentabilidade ou } \\
\text { afins) }\end{array}$ & 1,00 & 1,00 & 1,00 & 1,00 & 1,00 & 1,00 & 1,00 & 1,00 & 1,00 & 1,00 & 0,00 & 9,00 \\
\hline 9 & $\begin{array}{l}\text { Valor dos investimentos } \\
\text { ambientais }\end{array}$ & 0,50 & 0,50 & 0,50 & 0,50 & 0,50 & 0,50 & 0,50 & 0,00 & 0,50 & 0,50 & 0,00 & 4,00 \\
\hline 10 & $\begin{array}{l}\text { Prêmios e certificados relativos ao } \\
\text { meio ambiente }\end{array}$ & 0,50 & 0,50 & 0,50 & 0,50 & 0,50 & 0,50 & 0,30 & 0,50 & 0,50 & 0,50 & 0,50 & 4,80 \\
\hline 11 & $\begin{array}{l}\text { Eventos ambientais patrocinados } \\
\text { pela empresa }\end{array}$ & 0,25 & 0,25 & 0,25 & 0,25 & 0,25 & 0,25 & 0,25 & 0,00 & 0,25 & 0,25 & 0,25 & 2,25 \\
\hline \multirow[t]{2}{*}{12} & $\begin{array}{l}\text { Listagem em algum dos segmentos } \\
\text { diferenciados de Governança } \\
\text { Corporativa (N1, N2 ou Novo } \\
\text { Mercado) }\end{array}$ & 0,25 & 0,00 & 0,25 & 0,25 & 0,25 & 0,00 & 0,25 & 0,00 & 0,25 & 0,25 & 0,25 & 1,75 \\
\hline & Pontuação máxima & 14,5 & 11,25 & 9,50 & 14,50 & 9,50 & 10,25 & 11,63 & 9,50 & 12,50 & 13,83 & 8,00 & \\
\hline
\end{tabular}

No que tange à prestação de contas das metas ambientais previstas no ano anterior (Q.2), apenas a Vale, a GPA e a Ambev, apresentaram essa variável. As demais não divulgaram a prestação de contas de suas metas ambientais com relação ao ano anterior.

No que se refere à evidenciação de informações sobre efluentes, emissões e resíduos comparativos com os anos 
anteriores (Q.3), apenas três empresas não apresentaram essas informações em sua totalidade, Raízen, GPA e Ambev, recebendo notas 1, 1,33 e 1,33, respectivamente.

0 consumo de água em comparação com o ano anterior (Q.4) é evidenciado pela maioria das empresas, com exceção da Cosan que não divulgou esse dado. Ademais, de acordo com os dados comparativos, todas as empresas evidenciam a comparação do consumo de energia com o ano anterior (Q.5).

No caso de ser Integrante do índice Dow Jones de Sustentabilidade (DJSI) (Q.6) que analisa as práticas adotadas pelas empresas que tem ações na bolsa de valores, identificou-se que a maioria das empresas está dentro do âmbito sustentabilidade, exceto a Odebrecht.

Com relação a ser Integrante do Índice de Sustentabilidade (ISE) da BMeF Bovespa (Q.7) que analisa a performance das empresas e amplia o entendimento sobre grupos comprometidos com a sustentabilidade, diferenciando-os em termos de qualidade, nível de compromisso com o desenvolvimento sustentável, apenas as empresas Vale, GPA, Braskem e Ambev informaram no relatório de sustentabilidade que atendem a essa variável.

Em seguida, com base nas análises, observou-se que as empresas divulgam anualmente os relatórios com finalidade específica (relatório de sustentabilidade ou afins) (Q.8), com exceção da Cosan. A Odebrecht e a Cosan não divulgaram o valor dos investimentos ambientais (Q.9).

Quanto aos prêmios e certificados relativos ao meio ambiente (Q.10) a empresa que apresentou a menor pontuação foi a GPA tendo obtido apenas 0,30 e, no que tange aos eventos ambientais patrocinados pela empresa (Q.11), a Odebrecht não obteve nenhuma pontuação.

Por fim, em relação à listagem em algum dos segmentos diferenciados de Governança Corporativa (N1, N2 ou Novo
Mercado) (Q.12), não obtiveram pontuação a Petrobrás, Raízen e Odebrecht.

Em síntese, com relação às questões da pesquisa percebeu-se que o pior desempenho foi da prestação de contas (metas) ambientais em comparação com anos anteriores (Q.2), alcançando 6 de 20 pontos (30\%), seguido da listagem no ISE que alcançou desempenho fraco de 4 de 10 pontos (40\%). Esse fraco desempenho em uma questão estratégica (Q.2) pode ser considerado grave, pois não permite que os stakeholders façam uma análise prospectiva da viabilidade de longo prazo dos aspectos ambientais da empresa (por exemplo, os planos para evitar externalidades negativas derivadas dessa dimensão).

Na dimensão por empresa cabe destacar que, em média, os indivíduos da amostra alcançaram a pontuação de 11,05 de 14,50 , que representa $76,18 \%$ do todo. Portanto, infere-se que as empresas pertencentes à amostra, nesse período, apresentaram responsabilidade ambiental, com baixa propensão ao greenwash.

A Vale $(14,50)$, a Ambev $(13,83)$ e a Braskem $(12,50)$ foram as empresas com melhor desempenho no que diz respeito à evidenciação ambiental. Destacando a Vale, que foi a empresa com o pior desempenho econômicofinanceiro, mas não abriu mão das práticas superiores de sustentabilidade.

No âmbito inferior, a Cosan $(8,00)$ foi a empresa com pior desempenho ambiental, tendo alcançado apenas $55,17 \%$ do total da pontuação. Em seguida empataram com nove pontos no JBS, Ultrapar e Odebrecht, o que representa pouco mais de $65 \%$ do todo. Considera-se esse resultado preocupante, pois não são somente quatro dentre as dez maiores empresas brasileiras com baixo desempenho ambiental, outrossim, operam em atividades potencialmente poluidoras ou impactantes (açúcar e álcool, alimentício, químico e construção pesada), lidando 
com volume significativo de recursos naturais. Esses resultados corroboram com os achados por em Lins e Silva (2009), em que empresa importante de setor (papel e celulose), potencialmente, poluidora apresenta fraca transparência ambiental. Há um indício de greenwash dentre as empresas com pior desempenho relacionado a "certificações e rótulos duvidosos" (Lyon e Montgomery, 2015), pois apesar do fraco desempenho, as empresas divulgam prêmios, certificados e eventos patrocinados.

Por fim, salienta-se que mesmo tendo constatado uma baixa incidência de greenwash dentre as empresas da amostra, o estudo limitou-se a verificar o conteúdo que a empresa voluntariamente divulga em seus relatórios. Assim, não há garantia de que parte desse conteúdo não tenha apresentado viés de divulgação seletiva (Lyon e Montgomery, 2015).

Assim, como sugestões para pesquisas futuras pode-se avaliar a reputação da empresa pela repercussão positiva ou negativa de suas postagens em redes sociais, em aspectos relacionados à sua responsabilidade socioambiental (Eberle et al., 2013).

\section{Conclusões}

0 presente estudo teve como objetivo principal analisar a qualidade da evidenciação ambiental das dez maiores empresas brasileiras segundo o ranking da revista Valor Econômico, em 2016, considerando que a qualidade de diálogo com seus stakeholders revela responsabilidade ambiental verdadeira e não greenwash. 0 greenwash foi um termo criado para designar o desacoplamento entre o discurso e a prática de responsabilidade ambiental, isto é, empresas que dizem ser "verdes" ou afirma serem seus produtos "verdes", mas que na realidade não são. 0 greenwash é considerado como uma das razões para perda de credibilidade da sociedade nas ações ambientais promovidas pelas empresas em face da dificuldade de distinção do que é real engajamento com a causa de sustentabilidade e o que representa mero "marketing verde".

0 estudo utilizou um instrumento amplo com doze questões que consideram-se ser representativas de boas práticas de responsabilidade ambiental, pois foram baseadas em instrumento da B3 (2005) para destacar empresas ambientalmente eficientes. Baseado nos relatórios de sustentabilidade das companhias os quesitos do instrumento foram levantados e foi atribuído um escore por empresa e por questão.

A empresa de melhor desempenho foi a Vale que obteve pontuação máxima do instrumento $(14,50)$ e a pior foi a Cosan $(8,00)$ pontos, juntamente com outras três empresas de grande porte que alcançaram somente nove pontos. $\mathrm{O}$ agravante destacado para o fraco desempenho ambiental mensurado em $40 \%$ das maiores empresas brasileiras, foi que tais empresas integram atividades potencialmente poluidoras (combustíveis, química, construção pesada) e que tais empresas estampam em seus portfólios corporativos prêmios, certificados e patrocínios de eventos ambientais, o que as credencia como candidatas a prática de greenwash. No que tange a questão pior atendida pelas empresas destaca-se a ausência de planos e resultados de metas ambientais, o que revela a deficitária preocupação das empresas com a viabilidade de longo prazo de seus negócios, além de não oportunizar essa análise aos seus stakeholders.

0 estudo em questão procurou contribuir para a concepção de instrumentos de medida eficazes para a qualidade da divulgação ambiental das empresas, bem como permitir a identificação de práticas de greenwash, comprovadamente danosas à sociedade. 


\section{Conflito de interesses}

Os autores declaram não haver conflito de interesses.

\section{Referências}

B3. Índice de Sustentabilidade Empresarial (ISE). 2005. Disponível em: <http://www.bmfbovespa.com.br/pt_br/pro dutos/indices/indices-de-sustentabilidade/ indice-de-sustentabilidade-empresarialise.htm>. Acesso em: 24 jul. 2017.

Castro, F. A. R.; Siqueira, J. R. M.; Macedo, M. A. S. Indicadores ambientais essenciais: uma análise da sua utilização nos relatórios de sustentabilidade das empresas do setor de energia elétrica sul americano, elaborados pela versão "G3" da Global Reporting Initiative. Anais do 1st. South American Congress on Social and Environmental Accounting Research - CSEAR, Rio de Janeiro, UFRJ, 2009. p. 1-16. Disponível em: <http://www.csearsouthamerica.net/events /index.php/csear/csear2009/paper/view/2 3>. Acesso em: 02 fev. 2018.

CFC - Conselho Federal de Contabilidade. NBC-T 15 - Informações de natureza social e ambiental. 2004. Disponível em: <http://www.cfc.org.br/sisweb/sre/docs/R ES_1003.doc>. Acesso em: 13 ago. 2017.

Chen, Y.-S.; Chang, C.-H. Greenwash and green trust: The mediation effects of green consumer confusion and green perceived risk. Journal of Business Ethics, v. 114, n. 3, p. 489-500, 2013. https://doi.org/10.1007/ s10551-012-1360-0

CMMAD - Comissão Mundial Sobre Meio Ambiente e Desenvolvimento. Nosso futuro comum. Rio de Janeiro: Ed. FGV, 1991.

CONAR - Conselho Nacional de Autorregulamentação Publicitária. Código Brasileiro de Autorregulamentação Publicitária. 1977. Disponível em: <http://www.conar.org.br/>. Acesso em: 13 maio 2018.

Cooper, C. B. Rule 10b-5 at the intersection of greenwash and green investment: The problem of economic loss. Boston College Environmental Affairs Law Review, v. 42, n. 2, p. 405-437, 2015. Disponível em: <https://lawdigitalcommons.bc.edu/ealr/vol 42/iss2/5/>. Acesso em: 02 fev. 2018.

CVM - Comissão de Valores Mobiliários. Recomendações da CVM sobre Governança
Corporativa. 2002. Disponível em: <http://www.cvm.gov.br/export/sites/cvm/ decisoes/anexos/0001/3935.pdf>. Acesso em: 17 ago. 2017.

Degenhart, L.; Vogt, M.; Hein, N.; Rosa, F. S. Ranking setorial do grau de evidenciação ambiental das empresas brasileiras listadas no IBrX-100. REGE - Revista de Gestão, v. 23, n. 4, p. 326-337, 2016. https://doi.org/10.1016/j.rege.2016.07.002

Eberle, D.; Berens, G.; Li, T. The impact of interactive corporate social responsability communication on corporate reputation. Journal of Business Ethics, v. 118, n. 4, p. 731-746, 2013. https://doi.org/10.1007/ s10551-013-1957-y

Greer, J.; Bruno, K. Greenwash: The reality behind corporate environmentalism. Michigan: Ibon Foundation Incorporated, Third World Network, 1998.

Hendriksen, E. S.; Van Breda, M. F. Teoria da Contabilidade. São Paulo: Atlas, 1999.

Lins, L. S.; Silva, R. N.S. Responsabilidade socioambiental ou greenwash: uma avaliação com base nos relatórios de sustentabilidade ambiental. Sociedade, Contabilidade e Gestão, v. 4, n. 1, p. 91-105, 2009. Disponível em: <http://www.atena.org.br/revista/ojs2.2.3-06/index.php/ufrj/article/view/472>. Acesso em: 17 ago. 2017.

Leland, H.E.; Pyle, D. H. Information asymmetries, financial structure, and financial intermediation. The Journal of Finance, v. 32, n. 2, p. 371-387, 1977. https://doi.org/10.1111/j.1540-6261.1977. tb03277.x

Lyon, T. P.; Montgomery, A. W. Tweetjacked: The impact of social media on corporate greenwash. Journal of Business Ethics,

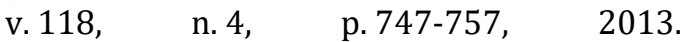
https://doi.org/10.1007/s10551-013-1958$\mathrm{x}$

Lyon, T. P.; Montgomery, A. W. The means and end of greenwash. Organizacional \& Environment, v. 28, n. 2, p. 223-249, 2015. https://doi.org/10.1177/108602661557533 2

Valor Econômico. As 1000 maiores e as campeãs em 25 setores e 5 regiões. 2016. Disponível em: <http://www.valor.com.br/ valor1000/2015>. Acesso em: 20 jul. 2017.

Ribeiro Filho, J. F.; Lopes, J.; Pederneiras, M. Estudando Teoria da Contabilidade. São Paulo: Atlas, 2009. 
Richardson, R. J. Pesquisa social: métodos e técnicas. São Paulo: Atlas, 2007.

Roesch, S. M. A. Projetos de estágio e de pesquisa em administração. 3. ed. São Paulo: Atlas, 2005.

Rosa, F. S.; Ensslin, S. R.; Ensslin, L. Evidenciação ambiental: processo estruturado de revisão de literatura sobre avaliação de desempenho da evidenciação ambiental. Sociedade, Contabilidade e Gestão, v. 4, n. 2, p. 24-37, 2009. Disponível em: <http://www.atena.org.br/revista/ojs2.2.3-08/index.php/ufrj/article/viewArticle/ 764>. Acesso em: 02 fev. 2018.

Silva, T. M. L.; Oliveira, E. A. G. "Maquiagem verde" na comunicação gráfica de condomínios residenciais em CaruaruPernambuco. A to Z, Novas Práticas em Informação e Conhecimento, v. 2, n. 2, p. 116-125, 2013. https://doi.org/10.5380/ atoz.v2i2.41326

Turano, L. M.; Cherman, A.; França, L. S. Sustentabilidade em uma grande corporação: uma análise da discrepância entre discurso e prática. Revista de Administração da UFSM, v. 7, edição especial, p. 111-128, 2014. https://doi.org/10.5902/1983465913043

Wilmshurst, T. D.; Frost, G. R. Corporate environmental reporting: A test of legitimacy theory. Accounting, Auditing e Accountability Journal, v. 13, n. 1, p. 10-26, 2000. https://doi.org/10.1108/0951357001 0316126 